\title{
A Pilot Oral Health Continuing Education Program in In-Hospital Medicine
}

\author{
Simon S. Kim $\mathrm{MD}^{1}$, Jacob Emge $\mathrm{MS}^{2}$, Brian J. Swann $\mathrm{DDs}^{3}$, Lori M. Balestrero $\mathrm{MD}^{4}$, R. Bruce Donoff DMD, $\mathrm{MD}^{5}$ and Sang E. Park DDs ${ }^{6 *}$ \\ ${ }^{1}$ Instructor in Medicine, Mount Auburn Hospital, Hospitalist Service - N 704, 330 Mt Auburn St., Cambridge, MA 02138, USA \\ 2DMD Candidate, Harvard School of Dental Medicine, 188 Longwood Avenue, Boston, MA 02115, USA \\ ${ }^{3}$ Assistant Professor of Oral Health Policy and Epidemiology, Harvard School of Dental Medicine, 188 Longwood Avenue, Boston, MA 02115, USA \\ ${ }^{4}$ Assistant Professor of Medicine, Mount Auburn Hospital, Hospitalist Medicine Service - South 414, 330 Mt Auburn St., Cambridge, MA 02138, USA \\ ${ }^{5}$ Dean, Harvard School of Dental Medicine, 188 Longwood Avenue, Boston, MA 02115, USA \\ ${ }^{6}$ Associate Dean for Dental Education, Harvard School of Dental Medicine, 188 Longwood Avenue, Boston, USA
}

${ }^{\star}$ Corresponding Author: Sang E. Park, Associate Dean for Dental Education, Harvard School of Dental Medicine, 188 Longwood Avenue, Boston, MA 02115, USA; Tel: +16174324247; Fax: +16174323881; E-mail: sang_park@hsdm.harvard.edu

Received: March 01, 2019; Accepted: March 11, 2019; Published: March 13, 2019;

\begin{abstract}
Objectives: The purpose of the project is to initiate an educational opportunity for hospital based physicians on their understanding of the relationship between oral health and systemic health. The project investigated the current level of oral health knowledge among medical health professionals.

Methods: Harvard School of Dental Medicine (HSDM) and Mount Auburn Hospital (MAH) offered an oral health session for in-patient clinicians (Hospitalists, Medicine Residents, and Physician Assistants) to investigate the current level of oral health knowledge among medical health professionals and introduce them to the concept of oral health. In-patient clinicians at MAH were asked to fill out a pre-session survey online, regarding their familiarity with basic oral health concepts and their comfort level with performing oral examinations, and a post-session survey on paper that repeated the pre-session questions.
\end{abstract}

Results: Fifty-three in-patient clinicians participated in the pre-session surveys, of which fourteen attended the educational information session and completed the post-session survey. Results showed that the session aided clinicians' understanding of the relevance of oral health in overall patient care.

Conclusion: The oral health education session can be a useful tool in contributing to awareness of oral health and understanding the link between oral diseases with systemic issues for in-patient clinicians.

\section{Introduction}

A greater integration of dental and medical education and practice provides options for prevention, diagnosis and therapy that can produce improvement for a team based, comprehensive approach to care. To deliver patient services in a more inter-professional and cost-conscious environment, oral health providers will require a more extensive preparation in basic biologic science and will engage in more extensive collaboration and interaction with other health providers, especially physicians. Conversely, physicians will need a greater understanding of oral health and its implications for overall health. The integration of oral health into overall medical care is essential especially for patients with chronic diseases, as oral health has been shown to be closely associated with cardiovascular disease, diabetes, and pregnancy outcomes [1-3]. It is important to engage clinicians across the health care professions in the prevention and detection of oral conditions. Oral health is integral to systemic health and our approach to patient care should reflect the need for collaboration among health care professionals for health promotion and maintenance. It is widely established that dental and oral diseases are closely connected to associated systemic health conditions and disease prevention [4-6]. Therefore, it is imperative that primary care medical professionals contribute in the treatment of oral diseases and the maintenance of good oral health. The Harvard School of Dental Medicine (HSDM) in conjunction with Mount Auburn Hospital $(\mathrm{MAH})$ offered an oral-health program to attending in-hospital physicians at MAH. This pilot program sought to introduce medical professions to the intraoral and extraoral examination as performed by dental professionals, and raise the physicians' awareness of the evident links between oral health and systemic health. The purpose of this study was to evaluate our pilot program by evaluating the physicians' perspectives on oral health and disease before and after the continuing education session on oral health.

\section{Methods}

\section{Educational contents and setting}

Harvard School of Dental Medicine (HSDM) and Mount Auburn Hospital (MAH) presented the first Oral Health Session for inhospital clinicians at MAH. Clinicians included Hospitalists, Medicine 
Physician Assistants, and Internal Medicine Residents. A ten-question pre-session survey was distributed electronically to participants. Upon completion of the oral health lecture, participants received a postparticipation survey at the end of the session. It took approximately five minutes to complete the survey. The inclusion criterion for participation was attending the oral health education seminar series. All post-participation surveys were completed using paper forms. The Oral Health Session was designed to give an overview of general oral anatomy and the experience of performing an oral examination. HSDM faculty presented topics on basic oral anatomy and oral health's relationship to systemic health and clinical oral health and dental treatment. Following the lectures, HSDM faculty supervised small group exercises (10 participants per group), which included a tutorial case study and hands-on oral examinations by the medical and dental students. Students were also given toothbrushes, toothpaste and dental floss as part of oral hygiene instructions upon completion of the session.

\section{Study design and data collection}

The survey-based quantitative study used the survey questionnaires based on a survey design from a previous study [7]. The final survey instrument included 10 questions measuring the perception of participating in-hospital physicians using a 5-point-Likert scale. Participants were asked to rate their perceived understanding of oral health topics, awareness of oral health's link to system health, and oral health's usefulness in overall patient care. Participation was voluntary and survey responses were collected anonymously through the online survey tool, Survey Monkey (CA, USA). The study was approved by the institutional review board (IRB) at all participating institutions including at Harvard Medical School (HMS)/ HSDM and MAH.

\section{Statistical analysis}

All analyses were performed using SPSS software version 15.0 (SPSS Inc., Chicago, IL, USA). For the 5-point-Likert scale, data contain the outcomes of a nonparametric Chi square to determine the association, if any, between pre-session and post-session reporting for each item. Likert Scale score for each survey question was noted for their significant difference at $\mathrm{p}<0.05$.

\section{Results}

Fifty-three clinicians completed the pre-session survey, of which 14 attended the oral health education session and completed the post-session survey. Pre-session survey results showed that in-patient clinicians who participated in the study had clinical experiences in the range of less than one to more than 15 years. Based on the postsession survey results, respondents generally found the session to be helpful in raising both their awareness of basic oral health issues and their comfort level with performing oral examinations. Table 1 shows the responses for questions on basic oral health issues and oral examinations on the pre-session and post-session surveys. Major findings from the pre-session data included that $40 \%$ of the participants were very or somewhat comfortable providing basic oral health information to patients before the session, which increased to $86 \%$ after the session. $45 \%$ of participants were very aware of the importance of oral health screenings before the oral health session, which increased to $71 \%$ after attending the education session. Also, $45 \%$ of participants were not very or not at all comfortable performing an oral examination before the session, and only $7 \%$ after the session. All participants (100\%) reported oral health is important to overall health and well-being, and they all agreed that it is important for primary care health professionals to collaborate with dentists after the oral health session.

The data showed statistically significant results at a p-value of $<0.05$ for five of the ten questions: awareness of the causes and prevention of periodontal disease, recognition of risks for oral disease, comfort with conducting an oral examination, provision of basic oral health information to patients, and whether it is important for health professionals to collaborate with dentists (Table 1).

\section{Discussion}

The findings in this study suggest that the oral health education session positively influenced how in-patient clinicians perceived the relationship between oral condition and overall systemic health. It is well established that oral health plays a significant role in one's morbidity and mortality [8]. The World Health Organization (WHO) emphasized the extent of this connection when their Global Oral Health Programme released the Oral Health Report of 2003. As outlined in this report, prevention of oral disease must be integrated with that of chronic disease as these conditions are tightly linked [9]. With over half of the US population over the age of 30 suffering from periodontitis or gingivitis, [10] it is critical to continue to find ways of expanding oral health promotion and disease prevention into patient care. One such method would be to expand the scope of care of physicians to include the prevention of oral disease.

In $2001,7.0 \%$ of the patients seeking dental-related care received treatment from a physician, with $2.7 \%$ receiving said care in the emergency department $[6,11]$. This is reflected in that 110 million dollars is spent yearly for services provided in the ED directly related to dental caries $[6,12]$. This care is palliative in nature, as patients usually receive prescription for antibiotics and pain medications without any treatment of the underlying active disease or without receiving an appropriate dental referral [6,13-15]. Although dental-related care in the ED is often less than ideal, many patients, especially those of the lower socio-economic status, are left with the ED as their only option because Medicaid does not cover care from a dental provider for most adults [6, 16-19]. Physicians encountering these patients lack the knowledge and comfort in discussing oral health, losing opportunities to counsel patients on the topic [6].

Fortunately, some medical schools are now trying to incorporate oral-health related topics into their curriculum as these subjects are now tested on Step 2 and Step 3 of the United States Medical Licensure Examination [20]. However, in 2009, the deans of education at over 69 U.S. medical schools admitted that they offer less than five hours of oral health curriculum or none at all [20]. In addition, in 2012, family medicine residency directors of US programs were surveyed, and only a third of respondents reported themselves as being satisfied with their residents' competency on the subject of oral health [21]. 
Sang E. Park (2019) A Pilot Oral Health Continuing Education Program in In-Hospital Medicine.

Table 1. Pre- and post-oral health session survey results of in-hospital physicians.

\begin{tabular}{|c|c|c|c|c|}
\hline Question & Category & Pre-Survey & Post-Survey & SD \\
\hline \multirow[t]{6}{*}{ Are you familiar with the causes, prevention, and signs of dental caries? } & Very & $7 \%$ & $36 \%$ & 6.6959 \\
\hline & & & & $\mathrm{p}=.153$ \\
\hline & Somewhat & $64 \%$ & $57 \%$ & \\
\hline & Neutral & $11 \%$ & 0 & \\
\hline & Not Very & $13 \%$ & $7 \%$ & \\
\hline & Not at All & $4 \%$ & 0 & \\
\hline \multirow[t]{6}{*}{ Are you familiar with the causes and prevention of periodontal disease? } & Very & $2 \%$ & $29 \%$ & 10.5971 \\
\hline & & & & $\mathrm{p}=.031$ \\
\hline & Somewhat & $60 \%$ & $50 \%$ & \\
\hline & Neutral & $9 \%$ & $7 \%$ & \\
\hline & Not Very & $21 \%$ & $14 \%$ & \\
\hline & Not at All & $7 \%$ & 0 & \\
\hline \multirow[t]{6}{*}{ Are you aware of links between tobacco use and oral cancer? } & Very & $68 \%$ & $93 \%$ & 4.607 \\
\hline & & & & $\mathrm{p}=.330$ \\
\hline & Somewhat & $28 \%$ & $7 \%$ & \\
\hline & Neutral & $4 \%$ & 0 & \\
\hline & Not Very & 0 & 0 & \\
\hline & Not at All & 0 & 0 & \\
\hline \multirow[t]{6}{*}{ Are you aware of the importance of oral health screening? } & Very & $45 \%$ & $71 \%$ & 2.2563 \\
\hline & & & & $\mathrm{p}=.689$ \\
\hline & Somewhat & $34 \%$ & $29 \%$ & \\
\hline & Neutral & $6 \%$ & 0 & \\
\hline & Not Very & $13 \%$ & 0 & \\
\hline & Not at All & $2 \%$ & 0 & \\
\hline \multirow[t]{6}{*}{ Can you recognize risks for oral disease? } & Always & $4 \%$ & $43 \%$ & 14.5452 \\
\hline & & & & $\mathrm{p}=.006$ \\
\hline & Sometimes & $60 \%$ & $50 \%$ & \\
\hline & Neutral & $17 \%$ & $7 \%$ & \\
\hline & Not Often & $15 \%$ & 0 & \\
\hline & Never & $4 \%$ & 0 & \\
\hline \multirow[t]{6}{*}{ Are you comfortable conducting an oral examination? } & Very & $2 \%$ & $21 \%$ & 10.9733 \\
\hline & & & & $\mathrm{p}=.027$ \\
\hline & Sometimes & $40 \%$ & $43 \%$ & \\
\hline & Neutral & $13 \%$ & $29 \%$ & \\
\hline & Not Very & $26 \%$ & $7 \%$ & \\
\hline & Not at All & $19 \%$ & 0 & \\
\hline \multirow[t]{3}{*}{ Are you comfortable providing basic oral health information to patients? } & Very & $6 \%$ & $36 \%$ & 10.8381 \\
\hline & & & & $\mathrm{p}=.028$ \\
\hline & Somewhat & $34 \%$ & $50 \%$ & \\
\hline
\end{tabular}




\begin{tabular}{|c|c|c|c|c|}
\hline Question & Category & Pre-Survey & Post-Survey & SD \\
\hline & Neutral & $19 \%$ & $14 \%$ & \\
\hline & Not Very & $32 \%$ & 0 & \\
\hline & Not at All & $9 \%$ & 0 & \\
\hline \multirow[t]{6}{*}{ How important is oral health to overall health and well-being? } & Very & $62 \%$ & $93 \%$ & 5.3535 \\
\hline & & & & $\mathrm{p}=.253$ \\
\hline & Somewhat & $32 \%$ & $7 \%$ & \\
\hline & Neutral & $6 \%$ & 0 & \\
\hline & Not Very & 0 & 0 & \\
\hline & Not at All & 0 & 0 & \\
\hline \multirow{6}{*}{$\begin{array}{l}\text { How important is it for primary care health professionals to collaborate } \\
\text { with dentists? }\end{array}$} & Very & $42 \%$ & $93 \%$ & 9.599 \\
\hline & & & & $\mathrm{p}=.048$ \\
\hline & Somewhat & $40 \%$ & $7 \%$ & \\
\hline & Neutral & $15 \%$ & 0 & \\
\hline & Not Very & $4 \%$ & 0 & \\
\hline & Not at All & 0 & 0 & \\
\hline
\end{tabular}

It is essential that physicians have an understanding of oral disease and its prevention, as collaboration between medical and dental providers is effective, especially in lower socio-economic groups [1, 22]. In addition, the interest among medical providers for training in oral health and disease is well established, $[6,23,24]$ and those who receive such training are proven to be equipped in diagnosing oral disease and making the appropriate dental referrals $[6,25,26]$. In addition, most states reimburse physicians for certain preventative measures of oral disease, such as the application of fluoride varnish, $[27,28]$ but $95 \%$ of medical professionals in the US have never applied varnish [29]. This may be attributed to a lack of comfort and knowledge, obstacles which may be overcome with physician-targeted training sessions. The future direction for this program involves further developing the oral health topics and measuring evidence of impact in the overall patient care experience. This project could have a significant effect on patient care outcomes. A medical professional who is aware of oral health conditions and cognizant of the link between oral and systemic health and can provide a higher level of care to patients, and projects that could measure the effect of this level of care on patient care outcomes are being designed.

\section{Conclusion}

An initial project to provide an educational opportunity for inpatient clinicians on oral health increased their understanding of the relationship between oral health and systemic health. Understanding of oral health knowledge among medical health professionals can play a positive role in overall patient care in linking oral diseases with systemic issues.

\section{References}

1. Hale KJ; American Academy of Pediatrics Section on Pediatric Dentistry (2003) Oral health risk assessment timing and establishment of the dental home. Pediatrics 111: 1113-1116. [crossref]
2. Mouradian WE, Reeves A, Kim S, Evans R, Schaad D, et al. (2005) An oral health curriculum for medical students at the University of Washington. Acad Med 80: 434-442. [crossref]

3. Donoff B, McDonough JE, Riedy CA (2014) Integrating oral and general health care. N Engl J Med 371: 2247-2249. [crossref]

4. Formicola AJ (2002) Dentistry and medicine, then and now. J Am Coll Dent 69: 30-34. [crossref]

5. Vargas CM, Isman RE, Crall JJ (2002) Comparison of children's medical and dental insurance coverage by sociodemographic characteristics, United States, 1995. J Pub Health Dent 62: 38-44.

6. Cohen LA (2013) Expanding the physician's role in addressing the oral health of adults. Am J Public Health 103: 408-412. [crossref]

7. Park SE, Donoff RB, Saldana F (2017) The Impact of Integrating Oral Health Education into a Medical Curriculum. Med Princ Pract 26: 61-65. [crossref]

8. Inglehart MR, Filstrup SL, Wandera A (2002) Oral health and quality of life in children. In Oral health- related quality of life. Chicago: Quintessence Publishing Co; Pg No: 79-88.

9. Petersen PE (2009) Global policy for improvement of oral health in the $21 \mathrm{st}$ century--implications to oral health research of World Health Assembly 2007, World Health Organization. Community Dent Oral Epidemiol 37: 1-8. [crossref]

10. Thornton-Evans G, Eke P, Wei L, Palmer A, Moeti R, et al. (2013) Periodontitis among adults aged $\geq 30$ years - United States, 2009-2010. MMWR Suppl 62: 129135. [crossref]

11. Cohen LA, Manski RJ (2006) Visits to non-dentist health care providers for dental problems. Fam Med 38: 556-564. [crossref]

12. Nalliah RP, Allareddy V, Elangovan S, Karimbux N, Allareddy V (2010) Hospital based emergency department visits attributed to dental caries in the United States in 2006. J Evid Based Dent Pract 10: 212-22. [crossref]

13. Graham DB, Webb MD, Seale NS (2000) Pediatric emergency room visits for nontraumatic dental disease. Pediatr Dent 22: 134-140. [crossref]

14. Tapper-Jones L (1993) A comparison of general medical and dental practitioners' attitudes to diagnosis and management of common oral and medical problems. Postgrad Educ Gen Pract 4: 192-197.

15. Lewis C, Lynch H, Johnston B (2003) Dental complaints in emergency departments: a national perspective. Ann Emerg Med 42: 93-99. [crossref]

16. US Department of Health and Human Services. Oral Health in America: A Report of the Surgeon General. Rockville, MD: National Institute of Dental and Craniofacial Research; 2000.

17. Katz S (2011) The individual and program impacts of eliminating Medicaid dental benefits in the Oregon Health Plan. Find Brief 14: 1-3. [crossref]

18. Smith VK, Gifford K, Ellis E, Rudowitz R, O'Malley Watts M, Marks C (2009) The Crunch Continues. New York: Kaiser Commission on Medicaid and the Uninsured Kaiser Family Foundation. 
19. McGinn-Shapiro M (2008) Medicaid coverage of adult dental services. State Health Policy Monit 2: 1-6

20. Ferullo A, Silk H, Savageau JA (2011) Teaching oral health in U.S. medical schools: results of a national survey. Acad Med 86: 226-230. [crossref]

21. Silk H, King R, Bennett IM, Chessman AW, Savageau JA (2012) Assessing oral health curriculum in US family medicine residency programs: a CERA study. Fam Med 44: 719-722. [crossref]

22. [No authors listed] (2000) Oral health in America: a report of the Surgeon General. $J$ Calif Dent Assoc 28: 685-695. [crossref]

23. Edwards PC, Kanjirath P (2010) Recognition and management of common acute conditions of the oral cavity resulting from tooth decay, periodontal disease, and trauma: an update for the family physician. J Am Board Fam Med 23: 285-294. [crossref]

24. Davis MM, Hilton TJ, Benson S, Schott J, Howard A, et al. (2010) Unmet dental needs in rural primary care: a clinic-, community-, and practice-based research network collaborative. J Am Board Fam Med 23: 514-522. [crossref]
25. dela Cruz GG, Rozier RG, Slade G (2004) Dental screening and referral of young children by pediatric primary care providers. Pediatrics 114: e642-652. [crossref]

26. Mouradian WE, Berg JH, Somerman MJ (2003) Addressing disparities through dental-medical collaborations, part 1 . The role of cultural competency in health disparities: training of primary care medical practitioners in children's oral health. $J$ Dent Educ 67: 860-868. [crossref]

27. Sams LD, Rozier RG, Wilder RS, Quinonez RB (2013)Adoption and implementation of policies to support preventive dentistry initiatives for physicians: a national survey of Medicaid programs. Am J Public Health 103: e83-90. [crossref]

28. Quinonez RB, Kranz AM, Lewis CW, Barone L, Boulter S, et al. (2014) Oral health opinions and practices of pediatricians: updated results from a national survey. Acad Pediatr 14: 616-623. [crossref]

29. Shimpi N, Schroeder D, Kilsdonk J, Chyou PH, Glurich I, et al. (2016) Medical Providers' Oral Health Knowledgeability, Attitudes, and Practice Behaviors: An Opportunity for Interprofessional Collaboration. J Evid Based Dent Pract 16: 19-29. [crossref]

\section{Citation:}

Kim SS, Jacob Emge, Swann BJ, Balestrero LM, Donoff RB, Park SE (2019) A Pilot Oral Health Continuing Education Program in In-Hospital Medicine. J Dent Maxillofacial Res Volume 2(1): 1-5. 